\title{
Optimized Economic Loading of Distribution Transformers Using Minimum Energy Loss Computing
}

\author{
Ayman Agha, ${ }^{1}$ Hani Attar, ${ }^{2}$ and Ashish Kr. Luhach ${ }^{3}{ }^{3}$ \\ ${ }^{1}$ Electrical Engineering Department, Philadelphia University, Amman, Jordan \\ ${ }^{2}$ Department of Energy Engineering, Zarqa University, Zarqa, Jordan \\ ${ }^{3}$ The PNG University of Technology, Lae, Papua New Guinea \\ Correspondence should be addressed to Ashish Kr. Luhach; ashish.kumar@pnguot.ac.pg
}

Received 6 July 2021; Revised 2 September 2021; Accepted 11 September 2021; Published 15 December 2021

Academic Editor: Sang-Bing Tsai

Copyright ( 92021 Ayman Agha et al. This is an open access article distributed under the Creative Commons Attribution License, which permits unrestricted use, distribution, and reproduction in any medium, provided the original work is properly cited.

This paper presents an approach to achieve the Economic Loading of Distribution Transformer (ELDT) based on minimizing the active energy loss. The effects of the transformer on-load and no-load losses, load factor (LF), and load loss factor (LSF) on the total energy losses are considered. The adopted technique in this paper consists of two phases, where ELDT is determined analytically in the first phase, and the load profile adequated (LSF) is statistically obtained in the second one. The results declare that the proposed technique is suitable for the shifts system mode of operation such as in industrial plants. Moreover, this paper investigates the effect of the total active and reactive power and energy losses on ELDT. Finally, numerical examples with software analyses are performed as a valuable tool, which supports the decision-makers to decide trustfully the size of the transformer and its capacity $(\mathrm{kVA})$ during the design stage, as well as to determine the economic loading during the operation based on the effective factors, that is, total power, energy losses, and the load profile.

\section{Introduction}

The key power system elements that affect the cost are the generators, transmission lines, and transformers; consequently, the maximum power system benefit is achieved when these elements operate at their maximum efficiency and minimum operational cost. Indeed, the appropriate design, selection, and operational conditions for the power system elements play a crucial factor in reducing the overall operational cost and hence improve the overall system efficiency and availability. The proposed work in this paper focuses on the power and energy losses of the transformer and its effect on the ELDT when waving the other system elements (generators and transmission lines).

The transformer is regarded as static equipment where most of the generated power passes through it at different stages. Moreover, the transformer is usually designed for a lifetime of 20 years or more. Apart from small-size transformers, the power and distribution transformer efficiencies usually vary from $95 \%$ to $98.5 \%$, taking into consideration the fact that these percentages are even higher for large-size transformers. Moreover, the vast number of transformers installed in a single power system makes the transformer design and its load be significant issues on the overall system cost, efficiency, and availability. Hence, the improper selection of transformers results in additional expenses added to the total investment value, extra cost to the power in terms of power and energy losses, and the extra availability/reliability of the overall system.

Based on the above, it is essential to optimize the transformer's loading versus the technical losses, which might have been placed during the power system operation period.

Different approaches were proposed to assess the technical and economic transformers' cost and design issues, such as in [1], where the reduction of overall losses in the distribution transformer was discussed. The impact of the transformer overexcitation on the loading conditions was investigated in [2]. The effect of the transformer location on cost minimization was introduced by [3], where [4] showed 
how to minimize the iron losses. The research work in [5] classified the losses of transformers into three groups of losses, which are tank losses, core joints losses, and stray losses. The determination of the no-load losses magnitude by using finite element analysis was presented in [6]. The authors of [7] proposed a mathematical model to determine the uncertainty of the transformer on-load and no-load losses. The usage of load loss factor is utilized in [8] to find the amount of the transformer power and energy losses. The reduction of the core cost which resulted from newly developed materials was given in [9]. In [10], the relationship between the no-load current and the level of the total harmonic distortion was investigated, wherein, in [11], the impact of the harmonic level over the nonlinear load was investigated in good detail. The work in [12] proposed a thermal model to monitor the operation and identify the hotspot points. The oil breakdown strength based on nanofluids was discussed in [13]. The developed methods to determine the transformer's life span considering the annual load factor were presented in $[14,15]$. In addition, the economics of the transformer and the evaluation of the total owning cost have been thoroughly discussed and analyzed in [3, 16-18].

In this paper, the ELDT is achieved for the transformer's capacity, based on the effective factors, parameters, and nature of the working mode during the transformer's lifetime operation.

The rest of the paper is arranged as follows. In Section 2, the formulation of the problem is presented, supported by the required mathematical equations, and the transformer losses calculations are presented in Section 3. In Section 4, numerical examples are shown for the proposed technique to simplify the understanding of implementing the technique. Finally, the results, conclusions, and future work proposals are presented in Section 5.

\section{Problem Formulation}

The optimum transformer loading is subject to all power and energy losses throughout the operational time, where one year is usually considered enough for the propose of the economic evaluation. Moreover, the objective function can be mathematically formulated as follows:

Find

$$
\left\{S_{L \text { (econ. })}\right\} \text {. }
$$

It is subject to

$$
S_{n} \geq S_{D} \geq S_{L(\text { econ })}
$$

And

$$
\Delta E=\Delta E_{\mathrm{NLL}}+\Delta E_{\mathrm{LL}}
$$

where $S_{L \text { (econ.) }}$ is the economic loading of the transformer $(\mathrm{kVA}), \Delta E_{\mathrm{LL}}$ is the on-load energy loss of the transformer $(\mathrm{kWh}), E_{\mathrm{NLL}}$ is the no-load energy loss of the transformer $(\mathrm{kWh}), S_{n}$ is the nominal capacity of the transformer $(\mathrm{kVA})$, $\Delta E$ represents overall average active energy losses (kWh), and $S_{D}$ is the designed capacity of the transformer (kVA).
In the other sections of this work, the authors look out to optimize the loading of the transformer by finding ELDT, which leads to finding the value of $S_{L(\text { econ.) }}$ in (1) in (kVA); this obtained value shall be less than the capacity of the transformer, which was determined during the design stage $S_{D}$ in (2) to avoid the overloading of the transformer (i.e., $S_{D} \geq S_{\mathrm{L}}$ (econ.). . Usually, the designed capacity (kVA) of the transformer is not matched with the standard unit capacity of the transformers; therefore, the designer should select a transformer with a unit size capacity that is nearest to greater standard capacity $\left(S_{n} \geq S_{D}\right)$. Consider the total energy losses $(\Delta E)(\mathrm{kWh})$ in (3), taking into account the future expansion in operation (if any) and the increase in the demand on power as illustrated in numerical examples in Section 4.

\section{Transformer Losses Calculation}

The current flows through the transformer windings, causing a power loss even if the secondary winding of the transformer is open. However, when the transformer is loaded, an additional power loss occurs. The flow of the current in the transformer windings causes active and reactive power losses. The active and reactive power losses in the transformer are explained as follows.

3.1. Transformer Active Power Losses. The active power losses $(\Delta P)$ caused by the current flow in the transformer are of two types, which are the iron losses or the no-load losses $\left(\Delta P_{\mathrm{Fe}}\right)$ and the copper losses or the on-load losses $\left(\Delta P_{\mathrm{Cu}}\right)$. The first active power losses are independent of the load current, which are called the iron losses or the no-load losses $\left(\Delta P_{\mathrm{Fe}}\right)$; they are hysteresis losses and eddy current losses. The second type of active power loss is due to the flow of the load current in the transformer's windings, which is called the copper losses or load losses $\left(\Delta P_{\mathrm{Cu}}\right)$. The total power losses $(\Delta P)$ then can be calculated from the sum of the power losses caused by the flow of active and reactive power which consist of two components. The first is the active power losses due to flow of active power $\left(\Delta P_{p}\right)$ and the second is active power losses due to the flow of reactive power $\left(\Delta P_{q}\right)$, expressed as follows:

$$
\Delta P=\Delta P_{p}+\Delta P_{q}
$$

where $\Delta P$ represents the total active power losses $(\mathrm{kW}) . \Delta P_{p}$ represents the active power losses due to the flow of active power $(\mathrm{kW}) . \Delta P_{q}$ represents the active power losses due to the flow of reactive power $(\mathrm{kW})$.

The active power losses of the transformer with respect to the transformer loading can be expressed as follows:

$$
\Delta P_{p}=\Delta P_{\mathrm{Fe}}+\Delta P_{\mathrm{Cu}} \cdot\left(\frac{S_{L}}{S_{n}}\right)^{2},
$$

where $\Delta P_{\mathrm{Cu}}$ represents active power on-load losses $(\mathrm{kW})$, $\Delta P_{\mathrm{Fe}}$ represents active power no-load losses $(\mathrm{kW})$, and $S_{L}$ represents the loading of the transformer $(\mathrm{kVA})$.

The values of $\Delta P_{\mathrm{Fe}}$ and $\Delta P_{\mathrm{Cu}}$ are usually a part of the transformer nameplate information or the technical data sheet of the transformer provided by the manufacturers. 
In addition, the flow of the reactive power is causing reactive power losses $(\Delta Q)$ related to the no-load current $\left(\Delta Q_{o}\right)$ and the on-load current $\left(\Delta Q_{L}\right)$, respectively. When the transformer is loaded with a power of $S_{L}$ of its nominal capacity $S_{n}$, then $\Delta Q$ with respect to the transformer loading can be presented as follows:

$$
\Delta Q=\Delta Q_{o}+\Delta Q_{L} \cdot\left(\frac{S_{L}}{S_{n}}\right)^{2},
$$

where $\Delta Q$ represents reactive power losses (kVAR), $\Delta Q_{L}$ represents reactive power on-load losses (kVAR), and $\Delta Q_{o}$ represents reactive power no-load losses (kVAR).

$\Delta Q_{o}$ and $\Delta Q_{L}$ can be calculated from the two following formulas, respectively:

$$
\begin{aligned}
& \Delta Q_{o}=\frac{I_{o \%}}{100} \cdot S_{n}, \\
& \Delta Q_{L}=\frac{\Delta V_{x \%}}{100} \cdot S_{n},
\end{aligned}
$$

where $I_{o \%}$ is the no-load current (\%) and $\Delta V_{x \%}$ is the impedance voltage of the transformer (\%).

Typically the value of current $\left(I_{\mathrm{o} \%}\right)$ is about $2.20 \%$ to $8.5 \%$ for distribution transformer and can even vary between $0.1 \%$ and $10 \%$ of total load current in some special transformers [10]. The value of $\Delta V_{x \%}$ usually varies between $3.5 \%$ and $6.5 \%$ and is up to $10 \%$ or more in some particular case transformers [19].

The flow of the reactive power causes a loss in active power which can be represented as an equivalent coefficient $\left(C_{e}\right)$. Thus the active power losses due to the flow of reactive power are expressed as follows:

$$
\Delta P_{q}=C_{e} \cdot \Delta Q,
$$

where $C_{e}$ is the equivalent coefficient converting the reactive power losses to active power losses (kW/kVAR).

Substituting (5) and (6) into (4) with considering (9) yields the total active power losses that are shown in the following formula:

$$
\Delta P=\Delta P_{F e}+\Delta P_{C u} \cdot\left(\frac{S_{L}}{S_{n}}\right)^{2}+C_{e} \cdot\left[\Delta Q_{o}+\Delta Q_{L} \cdot\left(\frac{S_{L}}{S_{n}}\right)^{2}\right] .
$$

The equivalent coefficient $C_{e}$ can be calculated from the expression in (11) according to [25] as follows:

$$
C_{e}=\frac{\partial}{\partial Q}\left(\frac{P^{2}+Q^{2}}{V^{2}}\right) \cdot R_{\operatorname{Tr}}=\frac{2 Q}{V_{n}^{2}} \cdot R_{\operatorname{Tr}},
$$

where $P$ is the active load power $(\mathrm{kW}), Q$ is the reactive load power ( $\mathrm{kVAR}$ ), and $R_{\mathrm{Tr}}$ is the transformer windings resistance $(\Omega)$.

The transformer windings resistance $R_{\operatorname{Tr}}$ according to [18] can be calculated as follows:

$$
R_{\mathrm{Tr}}=\Delta P_{\mathrm{Cu}} \cdot \frac{V_{n}^{2}}{S_{n}^{2}}
$$

3.2. Transformer Active Energy Losses. The product of the power losses $\left(\Delta P_{(t)}\right)$ integration over a time $(T)$ gives the energy losses $(\Delta E)$, and if the time-varying power losses $\Delta P_{(t)}$ over a time $(T)$ are arranged in descending order from $\Delta P_{(\max )}$ to $\Delta P_{(\min )}$ in equal integrated areas, then the active energy losses can be expressed as follows:

$$
\Delta E=\int_{0}^{T} \Delta P_{(t)} \mathrm{d} t=\Delta P_{(t)} \cdot T=\Delta P_{(\max .)} \cdot \tau,
$$

where $\tau$ is the equivalent load losses hours (h/year), $T$ represents the year's hours $=8760 \mathrm{~h}, \Delta P_{(t)}$ represents the time-varying active power losses $(\mathrm{kW})$, and $\Delta P_{(\max )}$ is maximum value of active power losses $(\mathrm{kW})$.

Substituting (10) into (13) yields the following formula:

$$
\Delta E=\left[\left(\Delta P_{F e}+C_{e} \cdot \Delta Q_{o}\right) T+\left(\Delta P_{C u}+C_{e} \cdot \Delta Q_{L}\right)\left(\frac{S_{L}}{S_{n}}\right)^{2}\right] \cdot \tau \text {. }
$$

3.3. The Transformer Power Economic Loading due to the Transferred Energy. If the time-varying loading power $\left(\mathrm{P}_{(t)}\right)$ over a time $(T)$ is arranged in descending order from $\mathrm{P}_{(\max )}$ to $\mathrm{P}_{(\mathrm{min})}$ in equal integrated areas, then the active energy consumed over a time period $\left(\mathrm{T}_{\text {eq }}\right)$ becomes

$$
E=\int_{0}^{T} P_{(t)} \mathrm{d} t=\Delta P_{(t)} \cdot T=P_{(\text {max. })} \cdot T_{\text {eq }}
$$

where $T_{\text {eq }}$ represents equivalent working hours over a year (h).

Based on the triangular power, the relation between the active power, apparent power of the transformer, and power factor $(\cos \varphi)$ is as follows:

$$
P_{(\max )}=S_{L} \cos \varphi,
$$

where $\cos \varphi$ is the power factor. Substituting (15) into (16) yields the following formula:

$$
E=S_{L} \cdot \cos \varphi \cdot T_{\text {eq }},
$$

where $E$ is the transferred energy in one year $(\mathrm{kWh})$.

The relative energy losses for the transformed energy over the year $(T=8760 \mathrm{~h})$ can be calculated by dividing transformer energy losses in (14) by the transformed energy in (17) which yields the following formula:

$$
\begin{aligned}
\frac{\Delta E}{E}= & \frac{\left(\Delta P_{\mathrm{Fe}}+C_{e} \cdot \Delta Q_{o}\right) \cdot T}{S_{L} \cdot \cos \varphi \cdot T_{\mathrm{eq}}} \\
& +\frac{\left[\left(\Delta P_{\mathrm{Cu}}+C_{e} \cdot \Delta Q_{L}\right) \cdot\left(S_{L} / S_{n}\right)^{2}\right] \cdot \tau}{S_{L} \cdot \cos \varphi \cdot T_{\mathrm{eq}}} .
\end{aligned}
$$

Equation (18) represents the relative active energy losses of the transformer. When performing some mathematical manipulation, the final relative active energy loss is 


$$
\begin{aligned}
\frac{\Delta E}{E}= & \frac{\left(\Delta P_{\mathrm{Fe}}+C_{e} \cdot \Delta Q_{o}\right) \cdot T_{\mathrm{eq}}}{S_{L} \cdot \cos \varphi \cdot T_{\mathrm{eq}}} \\
& +\frac{\left(\Delta P_{\mathrm{Cu}}+C_{e} \cdot \Delta Q_{L}\right) \cdot S_{L} \cdot \tau}{S_{L}^{2} \cdot \cos \varphi \cdot T_{\mathrm{eq}} \cdot S_{n}^{2}} .
\end{aligned}
$$

The minimum function is obtained when differentiating (19) with respect to $\left(S_{L}\right)$ and equalizing the result to zero as in (20), resulting in (21).

$$
\begin{gathered}
\frac{\mathrm{d}(\Delta E / E)}{\mathrm{d} S_{L}}=0 \\
-\frac{\left(\Delta P_{\mathrm{Fe}}+C_{e} \cdot \Delta Q_{o}\right) \cdot T_{\mathrm{eq}}}{S_{L}^{2} \cdot \cos \varphi \cdot T_{\mathrm{eq}}}+\frac{\left(\Delta P_{\mathrm{Cu}}+C_{e} \cdot \Delta Q_{L}\right) \cdot \tau}{\cos \varphi T_{\mathrm{eq}} \cdot S_{n}^{2}}=0 .
\end{gathered}
$$

In this case, $S_{L}$ is the optimum loading that is equal to $S_{L(\text { econ.) }}$; accordingly, the transformer optimum loading is obtained by performing some mathematical arrangement as shown in the following equation:

$$
S_{L \text { (econ. })}=S_{n} \sqrt{\frac{\left(\Delta P_{\mathrm{Fe}}+C_{e} \cdot \Delta Q_{o}\right) \cdot T_{\mathrm{eq}}}{\left(\Delta P_{\mathrm{Cu}}+C_{e} \cdot \Delta Q_{L}\right) \cdot \tau}} .
$$

The second derivative of (19) is checked and it is found that $\left(\mathrm{d}^{2}(\Delta E / E)\right) /\left(\mathrm{d} S_{l}^{2}\right)>0$, which means that the obtained result has a local minimum.

If the solution of equation (22) equals the standard unit size of the transformer, then the achieved solution is regarded as an optimum; however, if it does not equal the standard unit size (which is most probably), then the optimum solution will be obtained by selecting the nearest greater standard unit size; hence, the obtained solution is the economic loading.

In equation (22), the values of $T_{\mathrm{eq}}$ and $\tau$ are still unknown. However, $T_{\text {eq }}$ is determined in the following clause (4) of this section.

3.4. Equivalent Working Hours Determination. Based on the formula published in [20-22] which determines the equivalent working hours per month $\left(T_{(w / m) e q}\right)$ (also called maximum load utilization time), the expression of $T_{(w / m) e q}$ is shown in the following equation:

$$
\begin{aligned}
T_{(w / m) \text { eq. }}= & 2 \cdot D_{(w / y)} \cdot\left(\frac{n_{s}}{3}+\frac{3-n_{s}}{3} \cdot \frac{A_{p(a w)}}{A_{p(w)}}\right) \\
& +2 \cdot\left(365-D_{(w / y)}\right) \cdot \frac{A_{p(a w)}}{A_{p(w)}}, \\
T_{\text {eq }}= & N \cdot T_{(w / m) \text { eq }} .
\end{aligned}
$$

The proof of equations (23) and (24) will be introduced in Appendix A at the end of this study. In equations (23) and (24), $A_{p(w)}$ is the sum of the consumed active energies (day and night) during the time of operation per month $(\mathrm{kWh} / \mathrm{N})$, $A_{p(a w)}$ is the consumed active energy after the time of operation per month $(\mathrm{kWh} / \mathrm{N}), D_{(w / y)}$ is the number of working days over the year (excluding holidays, shutdowns, weekends, etc.), $n_{(h / m)}$ is the number of hours per month (i.e., year's hours/ 12 months $=730 \mathrm{~h}), n_{s}$ is the number of working shifts during the time of operation in one day, $T_{\text {eq }}$ represents the equivalent working hours $(\mathrm{h}), T_{(w / m) \text { eq }}$ represents the equivalent working time over the month in hours (h/month), and $N$ is The number of months $(N=1,2, \ldots, 12$, where $N=12$ for one year).

The equivalent working hours $\left(T_{\text {eq }}\right)$ in (24) can be calculated by multiplying $T_{(w / m) e q}$ in (23) with the number of the months, which is normally one year (12 months).

3.5. Maximum Loss Time Determination. Based on (13), where the energy loss is determined, and when the timevarying power losses values $\left(\Delta \mathrm{P}_{(t)}\right)$ are arranged in descending order from $\Delta P_{(\max )}$ to $\Delta P_{(\min )}$ as depicted in Figure 1, the areas under the curve of the dotted and straight line are equal.

Consider the relation between LSF and the year's hours ( $T=8760 \mathrm{~h}$ ) to obtain $\tau$ as in the following equation:

$$
\tau=\mathrm{LSF} \cdot T
$$

where LSF is load loss factor (unit less). When multiplying the LSF factor by the peak power losses $\left(\Delta \mathrm{P}_{(\max )}\right)$ for a period $(T)$, the overall average energy lost $(\Delta E)$ was given in [23].

Substituting (25) into (13) yields the following formula:

$$
\Delta E=\Delta P_{\max } \cdot T \cdot \mathrm{LSF} .
$$

The relationship between LF and LSF is given in [24], where the classical computational formula is presented as follows:

$$
\mathrm{LSF}=(1-k) \cdot \mathrm{LF}^{2}+k \cdot \mathrm{LF}
$$

The value of $k$ in (27) could be any value between zero and one. For instance, $k=0.2$ in the UK, 0.3 in the USA, and 0.33 in PL. In this paper and for the proceeding calculations, the value of $k$ is assumed as 0.33 .

Many authors in many literature works are using $k=0.30$ or $k=0.33$, which is appropriate to the urban power grid. In fact, the value of $k$ in (27) might have different values subject to the loads' profile curve. Hence, it is possible to obtain different mathematical equations by using the fitting curve techniques to represent the relation between LSF and LF for the analyzed period.

LF in equation (27) is defined as the ratio of the average load $\left(P_{(\mathrm{avg})}\right)$ supplied during the designated period $(T)$ to the maximum load $\left(P_{(\max )}\right)$ occurring in the same period (T) [25]. Consequently, LF can be expressed as follows:

$$
\mathrm{LF}=\frac{P_{(\mathrm{avg})}}{P_{(\max )}}=\frac{E}{P_{(\max )} \cdot T}=\frac{P_{(\max )} \cdot T_{(\mathrm{eq})}}{P_{(\max )} \cdot T}=\frac{T_{(\mathrm{eq})}}{T},
$$

where $P_{(\text {avg })}$ is the average load power $(\mathrm{kW})$. 


\section{Numerical Example}

The proposed method is implemented in a numerical example, where the calculations are as follows.

4.1. Load Input Data. It is intended to build an industrial plant with an expected maximum power of $584 \mathrm{~kW}$ to supply the processes requirement and associated buildings, with an expected power factor equaling 0.80 . The load is expected to increase in the future by $20 \%$.

The plant could initially work five days a week in one shift or two shifts or work continuously in three shifts and one shift off.

To find the ELDT, the calculation in this example is conducted to one shift of work: 8 hours a day, five days a week, excluding holidays. To maintain the process outside the working hours' time some of equipment and lighting remain ON (essential load). The amount of energy required to maintain the process outside the time of operation is equal to $20 \%$ of the energy consumed during the normal time of operation.

However, at the end of the example, the results of twoand three-shift modes of work are presented.

\section{Solution:}

Calculate:

(i) $T_{\text {eq }}$ represents the equivalent working hours (h).

The consumed energy (E) over the year is estimated by considering the essential load to maintain the plant in the running state after the working hours. It is calculated using the following formula: $\left(A_{p(a w)} / A_{p(w)}\right)=20 \%$.

$T_{\text {eq }}$ is calculated for one shift ( 8 hours a day, five days a week, excluding holidays, etc.), as in (23).

$$
\begin{aligned}
T_{(w / m) \text { eq. }}= & 2 \times 244\left(\frac{1}{3}+\frac{3-1}{3} \times \frac{20}{100}\right) \\
& +2(365-244) \times \frac{20}{100}=278.6 \mathrm{~h} / \mathrm{m} .
\end{aligned}
$$

And, based on equation (24),

$$
T_{\text {eq }}=12 \times 278.6=3343.2 \mathrm{~h} .
$$

(ii) $E$ is the active energy consumed over the year.

From equation (15), $E$ is obtained:

$$
E=584 \times 3343.2=1952.43 \mathrm{MWh} / \mathrm{yr} .
$$

(iii) $S_{L}$ is the apparent power of the load.

From equation (16), we obtain

$$
\mathrm{SL}=\frac{P_{(\max )}}{\cos \varphi}=\frac{584}{0.8}=730 \mathrm{kVA} .
$$

(iv) LF is the load factor.

Equation (28) is used to calculate the load factor:

$$
\mathrm{LF}=\frac{E}{P_{(\max )} \cdot T}=\frac{1952.43(\mathrm{MWh})}{584(\mathrm{~kW}) \times 8760(\mathrm{~h})}=0.382 .
$$

(v) LSF is load loss factor.

From equation (27), LSF can be calculated (for $k=0.333)$ as

$$
\mathrm{LSF}=\left[(1-0.333) \times 0.382^{2}+0.333 \times 0.382\right]=0.224086 \mathrm{~h} .
$$

(vi) $\tau$ represents the equivalent load losses' hours (h/ year).

By using equation (25), we obtain

$$
\tau=0.224086 \times 8760=1963 \mathrm{~h} .
$$

(v) $Q$ is reactive power load.

From the triangular power, for the relation between active, reactive, and apparent power, the reactive power equals

$$
\begin{aligned}
Q & =S_{L(\mathrm{Tr} .)} \cdot \sin \varphi=S_{L(\mathrm{Tr})} \cdot \sin (\cos \varphi)^{-1} \\
& =730 \times 0.6=438.51 \mathrm{kVAR} .
\end{aligned}
$$

(vi) $S_{n}$ is the nominal capacity of the transformer $(\mathrm{kVA})$. Considering the constraints in (2), the selection of the transformer capacity shall be equal to or more than the designed value; also, taking into account the future expansion in the load by $20 \%$, the capacity of the transformer $\left(S_{n}\right)$ is

$$
S_{n}=730 \times 1.2=876 \mathrm{kVA} .
$$

Round to the nearest standard available size, select a transformer with a capacity equal to $S_{n}=1000 \mathrm{kVA}$.

Based on (24), (25), (27), and (28), the load data for the one-shift mode of work is calculated. The result of the calculations is summarized in Table 1.

4.2. Transformers Technical Data. The technical data for the transformer (data belonging to transformer type (THUE23/ 1000) manufactured by ALSTHOM) which is provided in the manufacturer's technical data sheet and the calculated data are given in Table 2.

The given data of the transformer and the calculated data are summarized in Table 2, where $\Delta Q_{o}$ and $\Delta Q_{L}$ are calculated based on (7) and (8), respectively, as follows:

$$
\begin{aligned}
\Delta Q_{o} & =\frac{2.12}{100} \times 1000=21.20 \mathrm{kVAR}, \\
\Delta Q_{L} & =\frac{4}{100} \times 1000=50.00 \mathrm{kVAR} .
\end{aligned}
$$

Moreover, $R_{\mathrm{Tr}}$ and $C_{e}$ can be calculated based on (11) and (12), respectively, as follows: 


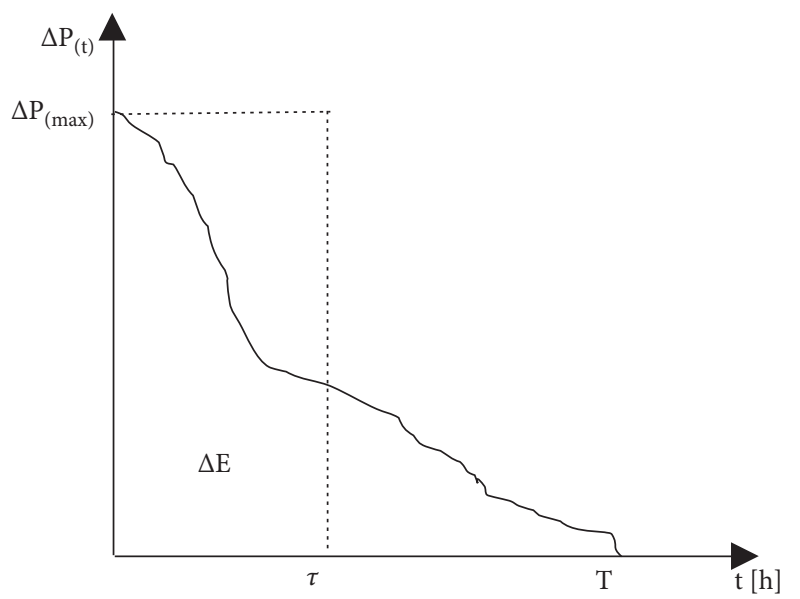

FIgURE 1: Electrical energy losses behavior [22].

TABLe 1: Load character data (calculated for one shift).

\begin{tabular}{lc}
\hline$E(\mathrm{MWh} / \mathrm{yr})$ & 1952.43 \\
$S_{L}(\mathrm{kVA})$ & 730.0 \\
$Q(\mathrm{kVAR})$ & 438.52 \\
$\mathrm{LF}(/)$ & 0.382 \\
$T_{\mathrm{eq}}(\mathrm{h} / \mathrm{yr})$ & 3343 \\
$\tau(\mathrm{h})$ & 1963 \\
\hline
\end{tabular}

TABle 2: Transformer $1000 \mathrm{kVA}$ technical data ${ }^{1}$.

\begin{tabular}{lccc}
\hline Given data & \multicolumn{2}{c}{ Calculated data } \\
Item & Value & Item & Value \\
\hline$S_{n}(\mathrm{kVA})$ & 1000 & $\Delta Q_{o}(\mathrm{kVAR})$ & 21.20 \\
$V_{n}(\mathrm{kV})$ & $6.6 / 0.4$ & $\Delta Q_{L}(\mathrm{kVAR})$ & 50.00 \\
$\Delta P_{\mathrm{Cu}}(\mathrm{kW})$ & 12.1 & $R_{\mathrm{Tr}}(\Omega)$ & 0.527 \\
$\Delta P_{\mathrm{Fe}}(\mathrm{kW})$ & 2.3 & $C_{e} \mathrm{~kW} / \mathrm{kVAR}$ & 0.1061 \\
$I_{\mathrm{o}}(\%)$ & 2.12 & - & - \\
$\Delta V_{\mathrm{sc}}(\%)$ & 4 & - & - \\
\hline
\end{tabular}

${ }^{1}$ Data belonging to transformer type (THUE23/1000) manufactured by ALSTHOM.

$$
\begin{aligned}
& R_{\mathrm{Tr}}=12.1 \times \frac{6.6^{2}}{1000^{2}} \times 1000=0.527 \Omega \\
& C_{e}=2 \times \frac{438.52}{6.6^{2} \times 1000} \times 0.527=0.1061 \mathrm{~kW} / \mathrm{kVAR} .
\end{aligned}
$$

4.3. Transformer Power Economic Loading. Based on the given data, the ELDT can be calculated from equation (22) for one working condition for one shift.

$$
S_{L(\text { econ. })}=1000 \times \sqrt{\frac{(2.3+0.1061 \times 21.2) \times 3343}{(12.1+0.1061 \times 50) \times 1963}}=667.21 \mathrm{kVA} \text {. }
$$

However, the ELDT for two shifts and that for three shifts are similar; the difference is only in calculating the time of $T_{\text {eq }}$ and $\tau$. The results for the work in shifts system are presented in Table 3.
TABLE 3: Transformer economic loading and working shifts.

\begin{tabular}{lccc}
\hline Shift number & One shift & Two shifts & Three shifts \\
\hline$S_{L \text { (econ) }}(\mathrm{kVA})$ & 667.21 & 607.81 & 552.76 \\
\hline
\end{tabular}

However, when neglecting the effect of $T_{\text {eq }}$ time and $\tau$ in (22), the ELDT reduces to 511 [kVA] for this transformer.

So, when selecting a transformer with less on-load losses by $25 \%, 50 \%$, and $78 \%$, where the no-load losses remain constant, the ELDT can be, respectively, increased to $72 \%$, $82 \%$, and $100 \%$.

A lot of exercises can be performed by the recently devolved software.

As a future application of the proposed approach, it can be used for future smart cities where high-performance energy systems in cooperation with many other technologies must be accessible, for example, IT infrastructure [26-28], wireless sensor systems [29], intelligent transport systems [30-32], industrial developments and cyber-physical systems [33-38], and monitoring systems [39-42].

\section{Results, Conclusions, and Future Work}

This paper presents a detailed approach for studying and calculating the ELDT. Different schedules of working hours for different transformers input technical data were taken into account. The evaluation shows that the ELDT is accruing when the objective is to minimize the active energy losses rather than active power losses, which was justified by the product of the equivalent working hours to the equivalent load losses, which is always more than or equal to one; the results of calculations are presented in Table 3.

The submitted formula for the ELDT shows the effect of the on-load losses (the copper losses) and the no-load losses (the core losses) on the result of the transformer economic loading. The optimality is achieved when the load losses are equal to no-load losses; however, this solution is very costly and sometimes practically is impossible; hence, a compromise is needed.

The explained numerical examples show the impact of the technical parameters (in terms of load and no-load losses) and operational time on the ELDT, where the ELDT could reach a value equal to or less than the transformer rated capacity. The more the relative value of the on-load losses to the no-load losses is reduced, the more enhancement of the ELDT is achieved, the utilization end is enhanced, and the operational cost of the transformer is reduced.

In addition, the software has been devolved to find the ELDT faster and easier, which is very beneficial, especially when having two or more transformers with different capacity and technical data working in parallel to feed a variable load.

This paper, along with the numerical examples, could be a base (platform) for other researches or future work, such as the effect of energy loss cost in terms of money on ELDT and the effect of load changing and power factor on the ELDT. 


\section{Appendix}

\section{A. Determination of Equivalent Working Hours}

The equivalent working time over one month $\left(T_{(w / m) \mathrm{eq}}\right)$ in hours (h) can be determined as the sum of the working hours during the time of operation (where the consumed energy is
$\left(A_{p(w)}\right)$ ), the time out of operation (where the consumed energy is $\left.\left(A_{p(a w)}\right)\right)$, and the time of consumed energy during the holidays time $\left(A_{p(h d)}\right)$. The three parts of time formulating the value of the equivalent working time are presented in the following equation:

$$
T_{(w / m) \text { eq. }}=\frac{n_{s}}{3} \cdot \frac{D_{(w / y)}}{365} \cdot n_{(h / m)}+\frac{3-n_{s}}{3} \cdot \frac{D_{(w / y)}}{365} \cdot n_{(h / m)} \cdot \frac{A_{p(a w)}}{A_{p(w)}}+\left(365-D_{(w / y)}\right) \cdot \frac{A_{p(a w)}}{A_{p(w)}} \cdot \frac{24_{(h / d)}}{12_{(m / y)}} .
$$

The equivalent working hours $\left(T_{\mathrm{eq}}\right)$ in equation (A.2) can be calculated by multiplying $T_{(w / m) \text { eq }}$ in equation (A.1) with the number of months.

$$
T_{\mathrm{eq}}=N \cdot T_{(w / m) \mathrm{eq}} \cdot
$$

The following is discussion on equation (A.1):

(i) When the plant works in three shifts' mode $\left(n_{s}=3\right)$, which is $8 \mathrm{~h} / \mathrm{shift}$ with no stoppages over the year (such as in airports and emergency departments, etc.), the number of working hours/year in this situation equals $D_{(w / y)}=365$ days/year. Thus, when applying this scenario in equation (A.1), the second and third parts of equation (A.1) turn to equal zero; as a result, only the first part of equation (A.1) remains.

(ii) When the plant works in three shifts' mode $\left(n_{s}=3\right)$, which is $8 \mathrm{~h} / \mathrm{shift}$ (excluding the duration of national holidays or/and shutdowns or/and weekends, etc.), when the load differs from that of normal operation day (like in chemical plants, big industrial factories, etc.), the remaining parts will be the first and third parts, since the value of the second part becomes zero. The second part's value becomes zero due to $n_{s}=3$. However, the value of the third part in equation (A.1) can be interpreted as follows:

$$
\left(365-D_{(w / y)}\right) \cdot \frac{A_{p(a w)}}{A_{p(w)}} \cdot \frac{24_{(h / d)}}{12_{(m / y)}},
$$

where (365: $\left.D_{(w / y)}\right)$ is the number of working days/ year (excluding holidays, etc., as above); and the value $\left(A_{p(a w)} / A_{p(w)}\right)$ represents the ratio between the active energies consumed (day and night) after and during the time of operation, multiplied by the number of hours per day $(24(\mathrm{~h} / \mathrm{d}))$ and divided by the number of months per year $(12(\mathrm{~m} / \mathrm{y}))$ to obtain the value of this part in hours per month.

(iii) When the plant works in one or two shifts, that is, $n_{s}=1$ or $n_{s}=2$, respectively, 5 days/week (excluding the public holidays and the time for maintenance and shutdown), such as in most public institutions, all the three parts of equation (A.1) will not equal zero as illustrated in the numerical example.

However, by substituting in equation (A.1), where $n_{(h / m)}$ $=730(\mathrm{~h}), n_{(h / m)} / 365=2$, and $\left(24_{(h / d)} / 12_{(m / y)}\right)=2$, we obtain the following equation:

$$
T_{(w / m) \text { eq. }}=2 \cdot D_{(w / y)} \cdot\left(\frac{n_{s}}{3}+\frac{3-n_{s}}{3} \cdot \frac{A_{p(a w)}}{A_{p(w)}}\right)+2 \cdot\left(365-D_{(w / y)}\right) \cdot \frac{A_{p(a w)}}{A_{p(w)}} .
$$

Equation (A.4) is the mathematical simplification of equation (A.1); however, both are the same.

Equation (A.4) determines the equivalent working time over the month $\left(T_{(w / m) \text { (eq.) }}\right.$ in hours), where $A_{p(w)}$ is the consumed active energy (day and night) during the time of operation per month $(\mathrm{kWh} / \mathrm{N}) . A_{p(a w)}$ is the consumed active energy (day and night) outside the time of operation per month $(\mathrm{kWh} / \mathrm{m})(\mathrm{kWh} / \mathrm{N}) . D_{(w / y)}$ is the number of working days over the year (excluding holidays, shutdowns, weekends, etc.). $n_{(h / m)}$ is the number of hours per month (i.e., year's hours $/ 2$ months $=730 \mathrm{~h}$ ). $n_{s}$ is number of shifts during the time of operation. $T_{\text {eq }}$ represents the equivalent working hours $(\mathrm{h}) . T_{(w / m) \text { eq. }}$ is the equivalent working time over the month in hours [h/month]. $N$ is the number of months $\left(N=1,2, \ldots, 12\right.$, where $N=12$ for one year). $24_{(h / d)}$ means twenty-four hours per day. $12_{(\mathrm{m} / \mathrm{y})}$ means 12 months per year.

\section{Data Availability}

The data that support the findings of this study are available from the corresponding author upon reasonable request.

\section{Conflicts of Interest}

The authors declare that they have no conflicts of interest. 


\section{References}

[1] J. C. Olivares, Y. Yilu Liu, J. M. Cañedo, R. Escarela-Pérez, J. Driesen, and P. Moreno, "Reducing losses in distribution transformers," IEEE Transactions on Power Delivery, vol. 18, no. 3, pp. 821-826, 2003.

[2] C. R. T. Castro, S. C. R. Barbosa, H. L. Ferreira, L. E. Samico, I. J. S. Lopes, and S.C. R. Silva, "Power transformer loading studies considering over excitation," in Proceedings of the 2004 IEEE/PES Transmission 8 Distribution Conference i3 Exposition: Latin America, Sao Paulo, Brazil, November 2004.

[3] R. S. da Cunha, J. R. Camacho, and S. C. Guimarães Jr., "Economic issues on load and transformer location in rural properties," in Proceedings of the 12th IEEE Mediterranean Electrotechnical Conference (IEEE Cat. No.04CH37521), IEEE Xplore, Dubrovnik, Croatia, May 2004.

[4] T. D. Kefalas, P. S. Georgilakis, A. G. Kladas, A. T. Souflaris, and D. G. Paparigas, "Multiple grade lamination wound core: a novel technique for transformer iron loss minimization using simulated annealing with restarts and an anisotropy model," IEEE Transactions on Magnetics, vol. 44, no. 6, pp. 1082-1085, 2008.

[5] J. C. Olivares-Galván, P. S. Georgilakis, and R. Ocon-Valdez, "A review of transformer losses," Electric Power Components and Systems, vol. 37, no. 9, pp. 1046-1062, 2009.

[6] G. U. Nnachi, A. O. Akumu, and C. G. Nicolae, "Estimation of no-load losses in distribution transformer design finite element analysis techniques in transformer design," in Proceedings of the 2018 IEEE PES/IAS PowerAfrica, pp. 527-532, Cape Town, South Africa, June 2018.

[7] V. M. Barbosa and R. P. Landim, "Estimation of the measurement uncertainty in the tests of electric distribution transformers filled with insulating liquid -no load loss and in load loss," Journal of Physics: Conference Series, vol. 1826, no. 1, Article ID 012094, 2021.

[8] H. Nyebuchi Amadi, "Analysis of power losses in $33 / 11 \mathrm{Kv}$ distribution feeder circuits via loss factor technique," Journal of Research in Engineering and Applied Sciences, vol. 5, no. 4, pp. 114-122, 2020.

[9] A. V. Vinogradov, A. V. Vinogradova, V. E. Bolshev, M. O. Ward, N. V. Makhiyanova, and L. V. Dolomaniuk, "Justification for creating a mobile complex to assess electric energy loss in power transformers during the operation process," E3S Web of Conferences in E3S Web of Conferences, vol. 124, pp. 1-4, Kazan, Russia, September 2019.

[10] A. H. Al-Haj and I. El-Amin, "Factors that influence transformer No-load current harmonics," IEEE Transactions on Power Delivery, vol. 15, no. 1, 2000.

[11] D. Koeva, S. Rachev, and L. Dimitrov, "Analysis of the power transformer operation supplying A combined non-linear load in the public sector - Part Ii: influence of the current harmonics," International Scientific Journal, vol. 1, pp. 37-40, 2020.

[12] M. Aslam, I. U. Haq, M. S. Rehan et al., "Dynamic thermal model for power transformers," IEEE Access, vol. 9, pp. 71461-71469, 2021.

[13] R. Krishnan S., "Experimental studies on breakdown strength of transformer oil based nanofluids: an overview," International Journal of Advanced Research, vol. 8, no. 9, pp. 148-154, 2020.

[14] J. Jiyu Wang, R. Ruijin Liao, Y. Yiyi Zhang, and F. Fanjin Meng, "Economic life assessment of power transformers using an improved model," CSEE Journal of Power and Energy Systems, vol. 1, no. 3, pp. 68-75, 2015.
[15] Y. Biçen, F. Aras, and H. Kirkici, "Lifetime estimation and monitoring of power transformer considering annual load factors," IEEE Transactions on Dielectrics and Electrical Insulation, vol. 21, no. 3, pp. 1360-1367, 2014.

[16] E. I. Amoiralis, M. A. Tsili, and A. G. Kladas, "Economic evaluation of transformer selection in electrical power systems," in Proceedings of the XIX International Conference on Electrical Machines-ICEM 2010, Rome, October 2010.

[17] W. D. A. S. Wijayapala, S. R. K. Gamage, and H. M. S. L. G. Bandara, "Determination of capitalization values for No load loss and load loss in distribution transformers," Engineer: Journal of the Institution of Engineers, Sri Lanka, vol. 49, no. 3, pp. 11-20, 2016.

[18] A. Agha, "Economic evaluation of transformer selection in distribution systems," Jordan Journal of Electrical Engineering (JJEE), vol. 4, no. 2, pp. 88-99, 2018.

[19] ABB, "Distribution transformers catalogue," http://ocw. uniovi.es/pluginfile.php/5422/mod_resource/content/1/Cat\% C3\%A1logo\%20transformadores\%20ABB.pdf.

[20] A. Agha, "A new algorithm for reactive power compensation in industrial plant," Jordan Journal of Electrical Engineering (JJEE), vol. 2, no. 3, pp. 241-252, 2016.

[21] A. A.-K. Agha, "A new approach for load loss factor estimation in electrical distribution networks," International Journal on Energy Conversion (IRECON), vol. 5, no. 5, pp. 148-153, 2017.

[22] A. Agha, H. Attar, A. Alfaoury, M. R. Khosravi, and Khosravi, "Maximizing electrical power saving using capacitors optimal placement," Recent Advances in Electrical \& Electronic Engineering (Formerly Recent Patents on Electrical \& Electronic Engineering), vol. 13, no. 7, pp. 1041-1050, 2020.

[23] T. Krishna, N. Ramana, and S. Kamakshaiah, "Loss estimation: a load factor method," Electrical and Power Engineering, vol. 4, no. 1, pp. 9-15, 2013.

[24] J. Keoliya and G. Vaidya, "Estimation of technical losses in a distribution system," Engineering Research and Technology, vol. 2, no. 6, pp. 2621-2626, 2013.

[25] A. Wu and B. Ni, Line Loss Analysis and Calculation of Electric Power Systems, Wiley\& Sons, Hoboken, NJ, USA, 1st edition, 2016.

[26] X. Chen and K. Siau, "Business analytics/business intelligence and IT infrastructure," Journal of Organizational and End User Computing, vol. 32, no. 4, pp. 138-161, 2020.

[27] C.-C. Huang, "User's segmentation on continued knowledge management system use in the public sector," Journal of Organizational and End User Computing, vol. 32, no. 1, pp. 19-40, 2020.

[28] N. Ramu, V. Pandi, J. D. Lazarus, and S. Radhakrishnan, “A novel trust model for secure group communication in distributed computing," Journal of Organizational and End User Computing, vol. 32, no. 3, pp. 1-14, 2020.

[29] M. R. Khosravi, H. Basri, H. Rostami, and S. Samadi, "Distributed random cooperation for VBF-based routing in highspeed dense underwater acoustic sensor networks," The Journal of Supercomputing, vol. 74, no. 11, pp. 6184-6200, 2018.

[30] M. Abbasi, M. Yaghoobikia, M. Rafiee, A. Jolfaei, and M. R. Khosravi, "Energy-efficient workload allocation in fogcloud based services of intelligent transportation systems using a learning classifier system," IET Intelligent Transport Systems, vol. 14, no. 11, pp. 1484-1490, 2020.

[31] M. Abbasi, A. Najafi, M. Rafiee, M. R. Khosravi, V. G. Menon, and G. Muhammad, "Efficient flow processing in 5G-envisioned SDN-based internet of vehicles using GPUs," IEEE 
Transactions on Intelligent Transportation Systems, vol. 22, no. 8, pp. 5283-5292, 2021.

[32] M. Abbasi, H. Rezaei, V. G. Menon, L. Qi, and M. R. Khosravi, "Enhancing the performance of flow classification in SDNbased intelligent vehicular networks," IEEE Transactions on Intelligent Transportation Systems, vol. 22, no. 7, pp. 4141-4150, 2021.

[33] X. Xu, R. Mo, X. Yin et al., "PDM: privacy-aware deployment of machine-learning applications for industrial cyber-physical cloud systems," IEEE Transactions on Industrial Informatics, vol. 17, no. 8, pp. 5819-5828, 2021.

[34] L. Qi, C. Hu, X. Zhang et al., "Privacy-aware data fusion and prediction with spatial-temporal context for smart city industrial environment," IEEE Transactions on Industrial Informatics, vol. 17, no. 6, pp. 4159-4167, 2021.

[35] M. Abbasi, E. Mohammadi Pasand, and M. R. Khosravi, "Workload allocation in iot-fog-cloud architecture using a multi-objective genetic algorithm," Journal of Grid Computing, vol. 18, no. 1, pp. 43-56, 2020.

[36] S. Meng, W. Huang, X. Yin et al., "Security-aware dynamic scheduling for real-time optimization in cloud-based industrial applications," IEEE Transactions on Industrial Informatics, vol. 17, no. 6, pp. 4219-4228, 2021.

[37] M. Abbasi, E. Mohammadi-Pasand, and M. R. Khosravi, "Intelligent workload allocation in IoT-Fog-cloud architecture towards mobile edge computing," Computer Communications, vol. 169, no. 71-80, 2021.

[38] X. Xu, B. Shen, X. Yin et al., "Edge server quantification and placement for offloading social media services in industrial cognitive IoV," IEEE Transactions on Industrial Informatics, vol. 17, no. 4, pp. 2910-2918, 2021.

[39] P. Tavallali, M. Yazdi, and M. R. Khosravi, "An efficient training procedure for viola-jones face detector," in Proceedings of the International Conference on Computational Science and Computational Intelligence (CSCI), Las Vegas, NV, USA, December 2017.

[40] M. R. Khosravi, O. Akbarzadeh, S. R. Salari, S. Samadi, and H. Rostami, "An introduction to ENVI tools for synthetic aperture radar (SAR) image despeckling and quantitative comparison of denoising filters," in Proceedings of the IEEE International Conference on Power, Control, Signals and Instrumentation Engineering (ICPCSI), Chennai, India, September 2017.

[41] M. Abbasi and M. R. Khosravi, "A robust and accurate particle filter-based pupil detection method for big datasets of eye video," Journal of Grid Computing, vol. 18, no. 2, pp. 305-325, 2020.

[42] P. Tavallali, M. Yazdi, and M. R. Khosravi, "A systematic training procedure for viola-jones face detector in heterogeneous computing architecture," Journal of Grid Computing, vol. 18, no. 4, pp. 847-862, 2020. 